\title{
Leishmania infantum and Dirofilaria immitis infections in Italy, 2009-2019: changing distribution patterns
}

Jairo Mendoza-Roldan ${ }^{1}$, Giovanni Benelli², Rossella Panarese ${ }^{1}$, Roberta latta ${ }^{1}$, Tommaso Furlanello33, Frederic Beugnet ${ }^{4}$, Andrea Zatelli ${ }^{1}$ and Domenico Otranto ${ }^{1,5^{*}}$

\begin{abstract}
Background: For long time, canine leishmaniosis (CanL) was considered endemic in the southern, central, and insular regions of Italy, whereas heartworm disease (HW) caused by Dirofilaria immitis was considered endemic in the northern region and in the swampy Po Valley. Following the reports of new foci of both diseases, in this study we update the distribution patterns and occurrence of new foci of CanL and HW discussing the main drivers for the changes in the epidemiology of these two important zoonotic canine vector-borne diseases.
\end{abstract}

Methods: Based on the statistical analyses of serological assays $(n=90,633)$ on L. infantum exposure and D. immitis infection performed by two reference diagnostic centres in Italy over a ten-year period (2009-2019) irrespective of the anamnesis of dogs. The distribution patterns of both parasites are herein presented along with the occurrence of new foci.

Results: Results highlighted the changing distribution patterns of L. infantum vs D. immitis infection in Italy. CanL is endemic in some areas of northern regions and HW has endemic foci in central and southern regions and islands. Significant differences in L. infantum exposure and HW infection prevalence among the study macroareas were detected. The overall results of the positive tested samples were $28.2 \%$ in southern Italy and islands, $29.6 \%$ in central Italy and $21.6 \%$ in northern Italy for L. infantum and $2.83 \%$ in northern Italy, $7.75 \%$ in central Italy and $4.97 \%$ in southern Italy and islands for HW. HW positivity significantly varied over years $\left(X^{2}=108.401, d f=10, P<0.0001\right)$, gradually increasing from $0.77 \%$ in 2009 to $8.47 \%$ in $2016-2017$.

Conclusions: New potential epidemiological scenarios are discussed according to a range of factors (e.g. environmental modifications, occurrence of competent insect vectors, transportation of infected animals to non-endemic areas, chemoprophylaxis or vector preventative measures), which may affect the current distribution. Overall, the results advocate for epidemiological surveillance programmes, more focussed preventative and control measures even in areas where few or no cases of both diseases have been diagnosed.

Keywords: Aedes mosquitoes, Canine vector-borne diseases, Dirofilaria immitis, Leishmania infantum, Sandflies

*Correspondence: domenico.otranto@uniba.it

1 Dipartimento di Medicina Veterinaria, Università degli Studi di Bari, Bari, Italy

Full list of author information is available at the end of the article

\section{Background}

In the last decades, canine vector-borne diseases (CVBDs) have been expanding worldwide due to several factors linked with increase in pet travelling along with owners, relocation of sheltered animals from endemic to previously non-endemic regions, as well as to the modification of the ecology of arthropod vectors and, importantly,

c) The Author(s) 2020. This article is licensed under a Creative Commons Attribution 4.0 International License, which permits use, sharing, adaptation, distribution and reproduction in any medium or format, as long as you give appropriate credit to the original author(s) and the source, provide a link to the Creative Commons licence, and indicate if changes were made. The images or other third party material in this article are included in the article's Creative Commons licence, unless indicated otherwise in a credit line to the material. If material is not included in the article's Creative Commons licence and your intended use is not permitted by statutory regulation or exceeds the permitted use, you will need to obtain permission directly from the copyright holder. To view a copy of this licence, visit http://creativeco mmons.org/licenses/by/4.0/. The Creative Commons Public Domain Dedication waiver (http://creativecommons.org/publicdomain/ zero/1.0/) applies to the data made available in this article, unless otherwise stated in a credit line to the data. 
environmental modifications [1-3]. Therefore, the spreading of new parasites and pathogens, and related infections, in previously non-endemic geographical areas poses major concerns to veterinary practitioners and, in the case of zoonotic ones, to public health officials [2]. The protozoan Leishmania infantum Nicolle and the nematode Dirofilaria immitis Leidy represent paradigmatic examples of the modification in the distribution of the diseases they cause (i.e. canine leishmaniosis, CanL, and heartworm disease, $\mathrm{HW}$ ). The expansion of the above diseases has been related to the distribution of their vectors (i.e. for CanL, sandflies of the genus Phlebotomus in the Mediterranean region; for HW, several mosquito species, belonging to the genera Aedes, Anopheles and Culex [4-7]).

In specific geographical contexts, such as Italy, where both CanL and HW have been endemic for long time [8], their ecology and distribution have been studied and new foci were reported by a retrospective analysis focusing on the period from 1990 to 2009 [1]. Indeed, until 1990, CanL was considered endemic in the southern, central and insular regions of Italy, whereas HW was considered endemic in the northern region and in the Po Valley [9, 10]. Sporadic case reports suggested that the distribution of both CVBDs has been changing, in that, dirofilariosis expanded towards the southern regions and CanL to the northern regions [1]. The spreading of dirofilariosis in previously non-endemic areas has been facilitated by the absence of chemoprophylaxis measures in the canine population, by using macrocyclic lactones (ML), as routinely performed in endemic areas of northern Italy [11]. Indeed, the only species of filarioid historically diagnosed in southern Italy have been Acanthocheilonema reconditum and Dirofilaria repens, causing less pathogenic subcutaneous filariosis $[12,13]$.

Meanwhile, the perception of clinicians and parasitologists has most likely changed, resulting into an increase of the requests for diagnostic tests of $D$. immitis infection in central-southern Italy, as well of $L$. infantum exposure in northern regions [8]. In this scenario, the aim of the present study is to analyse the results of serological assays performed by two reference diagnostic centres in Italy over a ten-year period (2009-2019), therefore providing a picture of the possible distribution patterns of CanL and HW.

\section{Methods}

Databases of serological tests in dogs from Italy

Databases from two diagnostic reference centres (hereafter reported as database A and B) were analysed (total number of serum samples $=90,633$ ). Italian macroareas were defined, according to the geopolitical classification, as northern, central and southern/islands macroareas (Fig. 1).

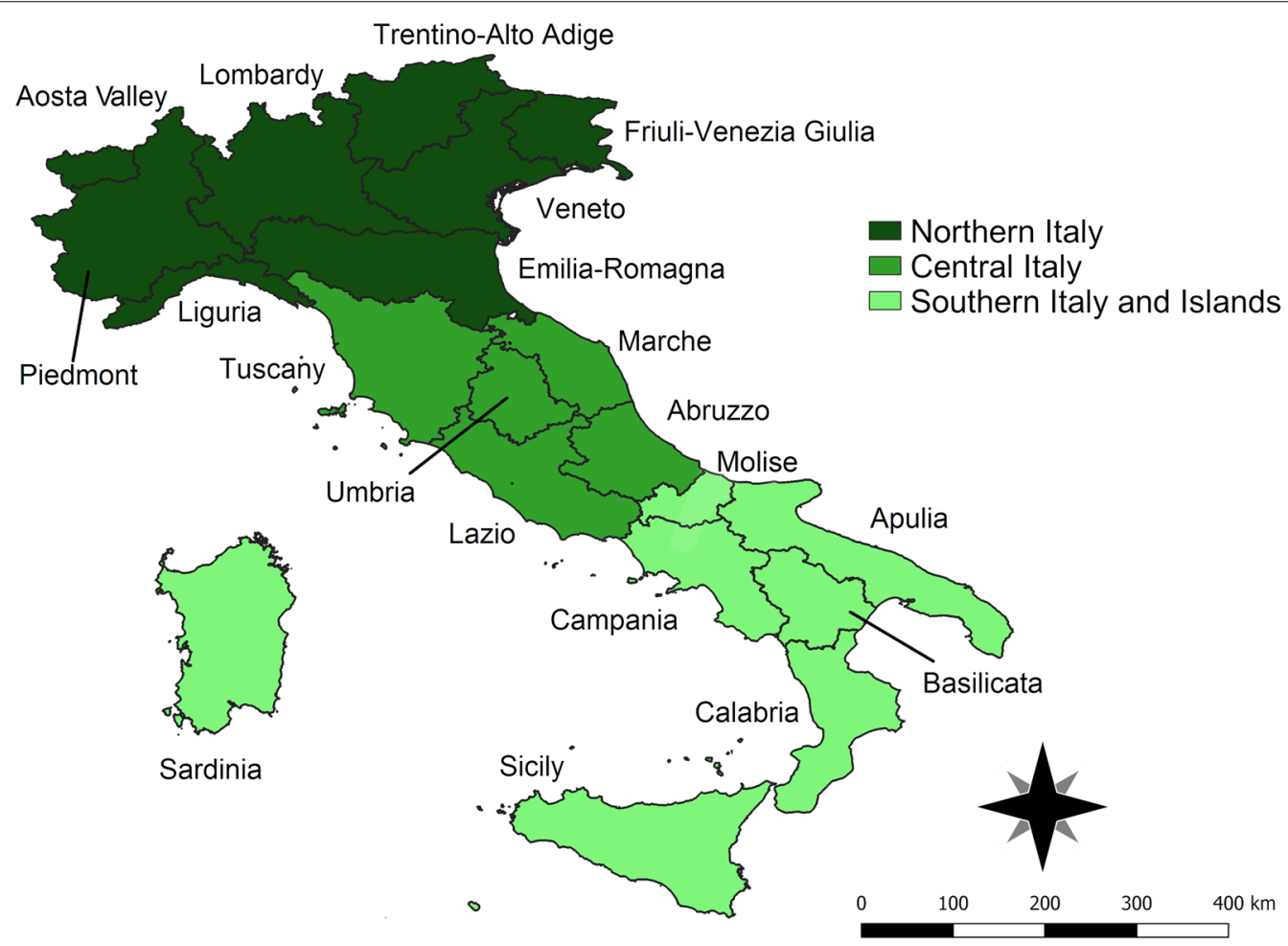

Fig. 1 Map of Italy showing the three main areas with their respective administrative regions 
The compiled data were included in the same database to observe significant variations on positive serological results. The database A included 64,375 records of dogs collected in a 10-year period (2009-2019) throughout the Italian Peninsula, including information regarding breed, sex and age (data not shown). Different serological (Novatec $^{\circledR}$ kit for CanL and Dirocheck Zoetis ${ }^{\circledR}$ for HW) enzyme-linked immune sorbent assay (ELISA) tests were used. Out of 64,375 records, 78 were excluded due to uncertainty of the origin of the samples.

The second dataset (B) included information of 26,258 of dogs examined from northern Italy (i.e. Emilia Romagna, Lombardia, Trentino-Alto Adige and Piedmont), central Italy (i.e. Lazio and Tuscany), and mainly from southern Italy and islands (i.e. Basilicata, Calabria, Campania, Apulia, Sicily and Sardinia) in a five-year period (2015-2019). This dataset also comprised information regarding breed, sex and age (data not shown), and serological (VetLine ${ }^{\circledR}$ Leishmania for CanL, sensitivity and specificity of $>98 \%$; and Filarcheck $96{ }^{\circledR}$ for HW, sensitivity of $97.6 \%$, specificity of $100 \%)$ ELISA, and an indirect semi-quantitative immunofluorescence test (MegaFLUO LEISH ${ }^{\circledR}$ for leishmaniosis, sensitivity of $96.9 \%$, specificity of $98.7 \%$ ) with positive or negative results. Out of 26,258 records, 70 were excluded due to uncertainty of the origin of the samples, and other 423 samples from the northern and central regions were not considered for the statistical analysis given that the data were biased by transportation of positive animals from endemic areas. However, for all included samples in both datasets no anamnestic data were available.

\section{Statistical analyses}

Differences in the prevalence of L. infantum exposure and $D$. immitis infection in the samples available from northern, central and southern Italy over time were analysed by JMP 9 (SAS) by using weighted generalized linear models (GLZ) with a binomial distribution to test model positive and negative serological outcomes. For each parasite, a GLZ with two fixed factors was used to assess significant differences in L. infantum or D. immitis positivity (i.e. prevalence) among the study macroareas over years: $y=X \beta+\varepsilon$, where $y$ is the vector of the observation (i.e. serological outcome: positive $=1$, negative $=0), X$ is the incidence matrix, $\beta$ is the vector of fixed effects (the study macroarea: northern, central or southern Italy and islands; and years), and $\varepsilon$ is the vector of the random residual effects $(P=0.05)$.

Then, a dataset was created for each study macroarea and a GLZ with two fixed factors was used to evaluate significant differences in L. infantum or D. immitis positivity between the regions and years within a given macroarea; the structure of the GLZ was identical to the above described one, with two fixed effects (i.e. the study region and year). A $P$-value of 0.05 was used as a threshold to assess significant differences among values. To verify that the changing distribution patterns of $L$. infantum and D. immitis were not random, a contingency analysis assessing the relationship between the $L$. infantum and D. immitis positivity in the various macroareas, regions and study years was also carried out [14].

Serological data were presented in terms of annual and cumulative prevalence; distribution maps of cumulative positive cases for $L$. infantum and D. immitis were generated using QGIS version 3.4.4-Madeira [15].

\section{Results}

Overall, the number of serological tests performed for L. infantum $(n=80,309)$ in the three areas of Italy is reported in Table 1, being higher in southern Italy $(37.7 \%$ of all tests performed) than in central Italy (31\%), and northern Italy (24.7\%). Conversely, the overall number of tests requested for the diagnosis of $D$. immitis throughout Italy $(n=10,324)$ was significantly lower $(11.3 \%$ of all the requested serological tests) than that for L. infantum, with a relative high number in northern Italy $(51.7 \%$ of all tests performed) and the lowest in southern Italy (Table 1).

Data showed a significant difference in L. infantum prevalence between the different study macroareas $\left(\chi^{2}\right.$ $=218.564, d f=2, P<0.0001)$, with an overall positivity of $28.2 \%$ in southern Italy and islands, $29.68 \%$ in central Italy and $21.62 \%$ in northern Italy (Table 1, Fig. 2). The impact of the study year on L. infantum results in Italy was also significant $\left(\chi^{2}=559.846, d f=10, P<0.0001\right)$, with values $>30 \%$ in 2011, 2012, 2014 and 2015. Dirofilaria immitis prevalence showed significant differences between the study macroareas $\left(\chi^{2}=114.879, d f=2, P\right.$ $<0.0001$ ), being of $2.83 \%$ in northern Italy, $7.75 \%$ in central Italy and $4.97 \%$ in southern Italy and islands. On the whole Italian territory, the number of HW positive tests significantly varied over years $\left(\chi^{2}=108.401, d f=10, P<\right.$ 0.0001 ), gradually increasing from $0.77 \%$ in 2009 to values ranging between $5.19-8.47 \%$ in 2016-2017 (Table 1, Fig. 3).

Table 1 Number ( $n$ ) and percentage of serological tests positive for canine leishmaniosis and hearthworm disease in three main macroareas of Italy

\begin{tabular}{llll}
\hline Species & $\begin{array}{l}\text { North } \\
n(\%)\end{array}$ & $\begin{array}{l}\text { Centre } \\
n(\%)\end{array}$ & $\begin{array}{l}\text { South and islands } \\
n(\%)\end{array}$ \\
\hline Leishmania infantum & $\begin{array}{l}4664(21.6) \\
(\text { Total: } 21,545)\end{array}$ & $\begin{array}{l}7801(29.6) \\
(\text { Total: 26,128) }\end{array}$ & $\begin{array}{l}9208(28.2) \\
(\text { Total: 32,610) }\end{array}$ \\
Dirofilaria immitis & $\begin{array}{l}151(2.8) \\
\text { (Total: 5335) }\end{array}$ & $\begin{array}{l}243(7.5) \\
\text { (Total: 3119) }\end{array}$ & $\begin{array}{l}93(4.9) \\
\text { (Total: 1866) }\end{array}$ \\
\hline
\end{tabular}




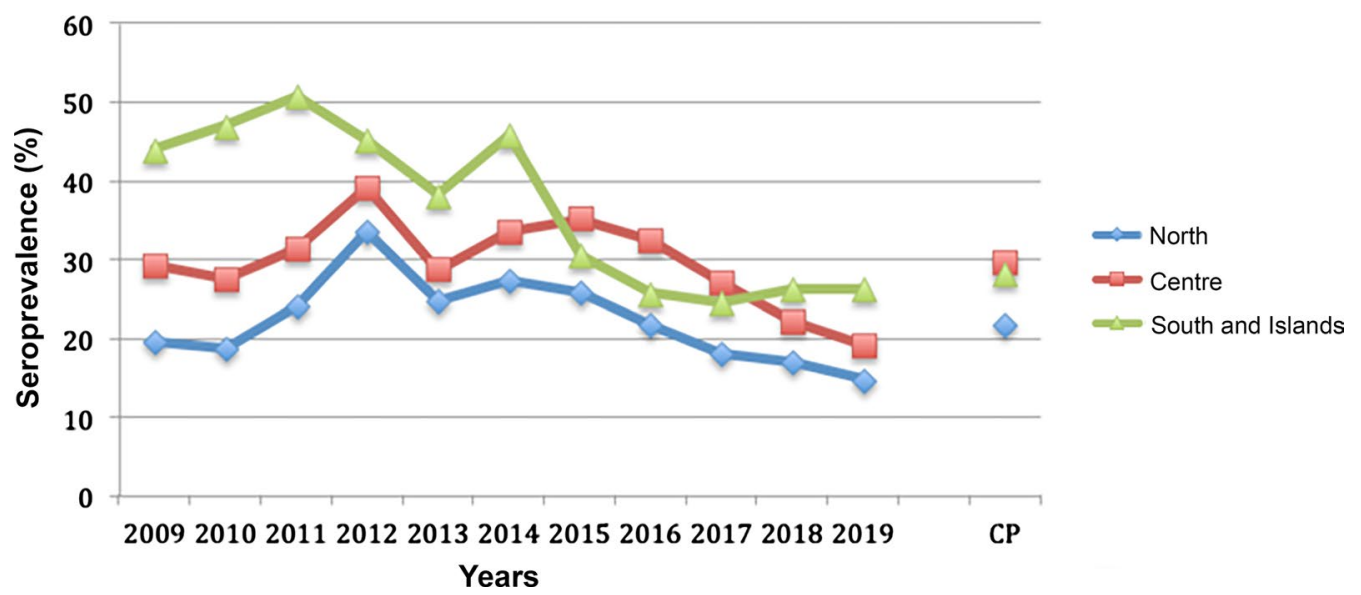

Fig. 2 Pattern of mean annual seroprevalence of canine leishmaniosis in the three main macroareas of Italy. The cumulative prevalence (CP) is also shown

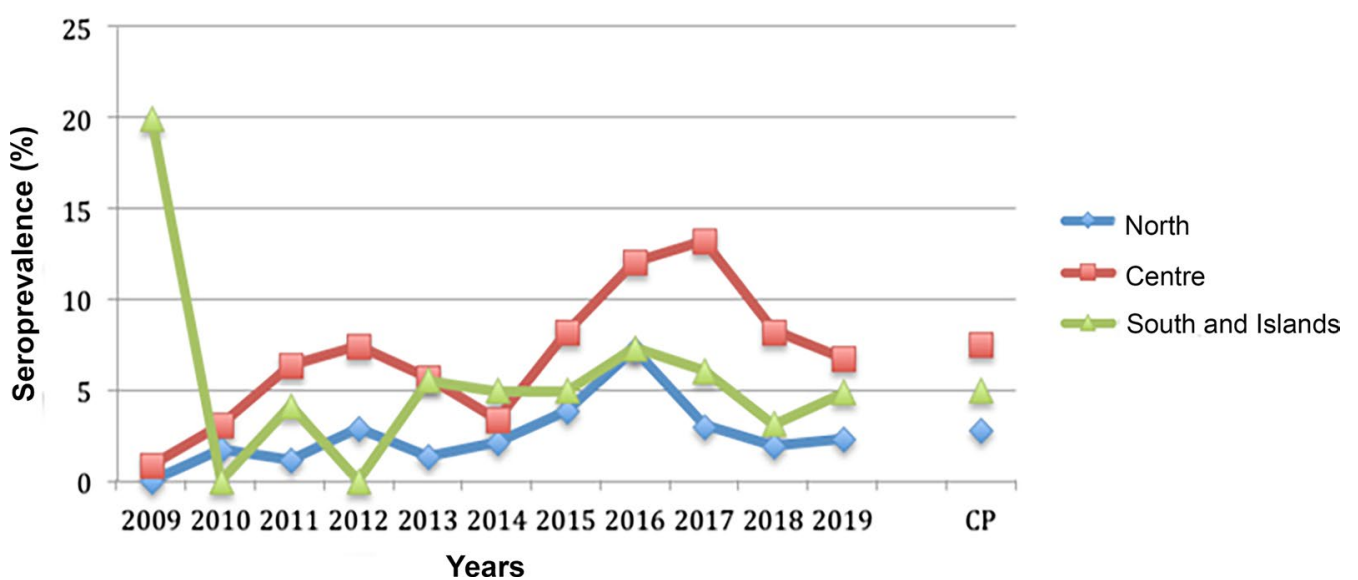

Fig. 3 Pattern of mean annual seroprevalence for Dirofilaria immitis in the three main macroareas of Italy. The cumulative prevalence (CP) is also shown

A detailed analysis of the trends of prevalence for $D$. immitis and $L$. infantum over time in the three Italian macroareas was provided by assessing the impact of the study year and region on prevalence for both pathogens. In northern Italy, $L$. infantum prevalence showed significant differences over the study years $\left(\chi^{2}=286.277, d f\right.$ $=10, P<0.0001$ ), being highest in 2012 and 2014 (i.e. $33.51 \%$ and $27.27 \%$, respectively) (Fig. 2). Notably, significant variations in tests positive for L. infantum among the various northern Italy regions were recorded $\left(x^{2}=\right.$ 190.657, $d f=7, P<0.0001$ ), with the highest values in Piedmont, Trentino Alto Adige, Aosta Valley and Friuli Venezia Giulia $(28.93 \%, 27.59 \%, 27.40 \%$ and $27.17 \%$, respectively). The study year and region significantly impacted the results of $D$. immitis in northern Italy $\left(\chi^{2}\right.$ $=56.954, d f=10, P<0.0001$; and $\chi^{2}=40.555, d f=7$,
$P<0.0001$, respectively), with the highest prevalence observed in 2016 (7.20\%) (Fig. 3). The highest prevalence rate of $D$. immitis were recorded in Aosta Valley(11.36\%), Trentino Alto Adige (7.41\%) and Piedmont (6.29\%), while the lowest was found in Veneto (2.12\%).

In central Italy, both the study year and region led to significant differences in $L$. infantum prevalence $\left(\chi^{2}=\right.$ 371.252, $d f=10, P<0.0001$; and $\chi^{2}=609.769, d f=5, P<$ 0.0001 , respectively). It was more than $30 \%$ in 2012,2014 , 2015 and 2016 (Fig. 2), with the highest values in Lazio (38.52\%), followed by Umbria (35.61\%) and Abruzzo (34.10\%). Positive results for $D$. immitis were also affected by the study year $\left(x^{2}=55.333, d f=10, P<0.0001\right)$, showing values of $>10 \%$ in 2016 (i.e. 12.1\%) and 2017 (i.e. 13.32\%) (Fig. 3). Significant differences in the prevalence for $D$. immitis were noted in central Italy $\left(\chi^{2}=80.975\right.$, 
$d f=4, P<0.0001$, respectively) with the highest values recorded in Tuscany $(11.48 \%)$ and Marche $(7.84 \%)$.

In southern Italy and islands, $L$. infantum positive tests were significantly different among the study years $\left(\chi^{2}=\right.$ 201.963, $d f=10, P<0.0001$ ), with values ranging from $24.55 \%$ (2017) to $50.66 \%$ (2011) (Fig. 2). Leishmania infantum results in this macroarea also showed significant differences between regions $\left(\chi^{2}=642.949, d f=6\right.$, $P<0.0001)$ with the highest values recorded in Molise (54.26\%), Sicily (50.18\%) and Sardinia (38.34\%). On the other hand, the study region did not play a significant role impacting $D$. immitis prevalence, even if a trend was observed ( $\chi^{2}=10.723, d f=6, P=0.10$, respectively). Indeed, the largest number of analysed samples was from Apulia $(n=1608)$, followed by Basilicata $(n=80)$ and Sardinia $(n=70)$. Considering regions with sample size $>40$, the largest number of positive tests were from Sardinia and Apulia (10\% and 4.73\%, respectively). The effect of the study year was not significant $\left(\chi^{2}=16.145, d f=10\right.$, $P=0.136)$ due to the limited number of samples examined during 2009-2014 (i.e. $n=117$ ), at variance with the larger number of samples during 2015-2019 (i.e. $n=$ 1729).

Contingency results obtained analysing the separate datasets for each study macroarea are given in Additional file 1: Table S1. Overall, the observed changing distribution patterns of $L$. infantum and D. immitis in Italy were not random or due to a biased sampling over the different areas and years ( $L$. infantum, macroarea: $\chi^{2}=$ 486.62, $d f=2, P<0.0001$; year: $\chi^{2}=827.903, d f=10$, $P<0.0001$, respectively; $D$. immitis, macroarea: $\chi^{2}=$ 104.545, $d f=2, P<0.0001$; year: $X^{2}=99.070, d f=10$, $P<0.0001$, respectively). Serological $L$. infantum results had a similar cumulative prevalence throughout the Italian territory (Fig. 2), showing an annual slight decrease in all the regions, from 2015 to 2018. Leishmania infantum was widely distributed throughout the Italian Peninsula, with a number of positive animals $>400$ in the central (Lazio and Tuscany) and southern (Apulia and Basilicata) regions as well as in both islands (Sardinia and Sicily). In addition, provinces with $>300$ positive samples were in the northern regions (i.e. Turin, Piedmont and Vicenza, Veneto) (Table 1, Fig. 4).

The highest percentage of positive tests of $D$. immitis was registered in the central regions (i.e. Tuscany and Lazio) followed by the southern and northern regions with annual variation patterns throughout the observation period (Fig. 3). An overall lower number of samples was positive for D. immitis compared to L. infantum, with $>10$ positive cases recorded in three provinces in the northern Italy (i.e. Turin, Piedmont; Genova, Liguria;

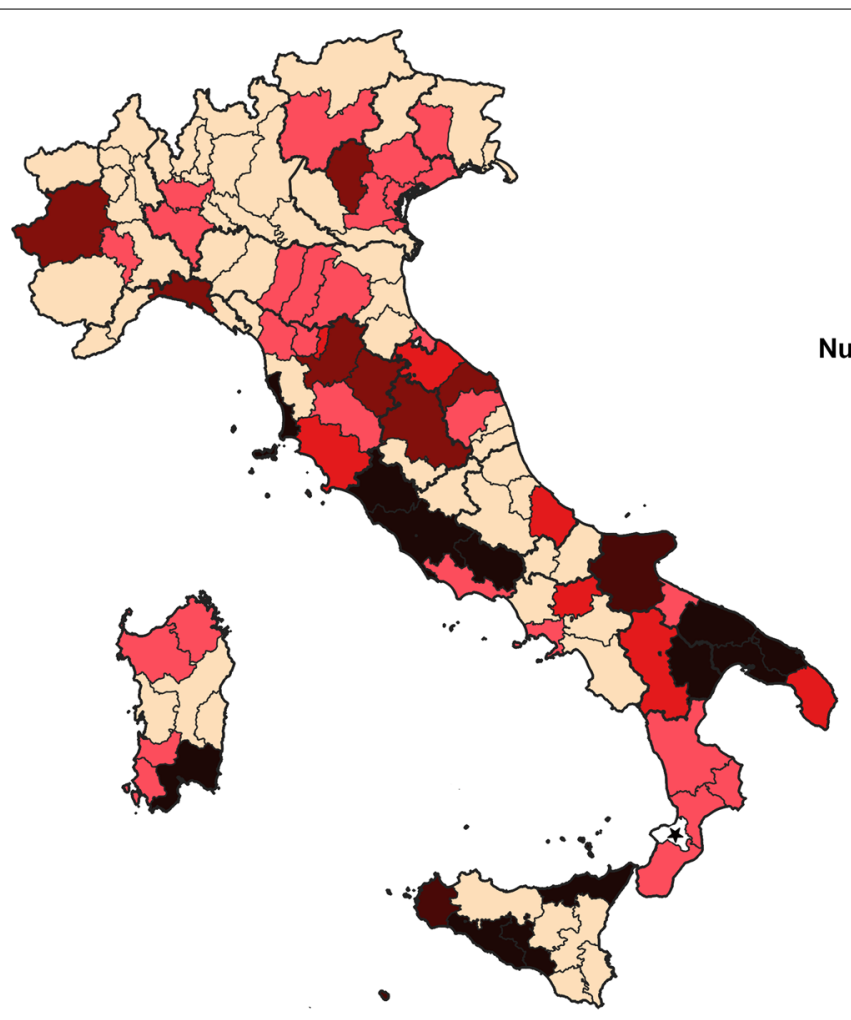

Number of positive samples (2009 - 2019)
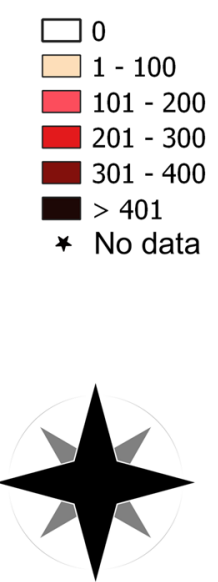

$\begin{array}{lllll}0 & 100 & 200 & 300 & 400 \mathrm{~km}\end{array}$

Fig. 4 Distribution map with number of cases (2009-2019) per province of CanL in Italy 
and Belluno, Veneto). In central Italy, the province with the greatest number of $\mathrm{HW}$ cases (i.e. Florence, Tuscany) was surrounded by provinces with more than 20 positive samples (i.e. Bologna, Emilia Romagna; Arezzo and Prato, Tuscany). The largest number of positive samples in southern Italy was recorded in the Apulia region (i.e. Brindisi and Lecce provinces). No data were available for four provinces of the North (i.e. Biella, Piedmont; Lecco, Lombardy; Piacenza, Emilia Romagna; and Verona, Veneto), for two provinces of southern Italy (i.e. Isernia, Molise; Vibo-Valentia, Calabria), and many provinces of the islands (i.e. Nuoro and Oristano, Sardinia; Agrigento, Caltanissetta and Ragusa, Sicily) (Table 1, Fig. 5).

\section{Discussion}

Based on the results of this large dataset $(n=90,633)$ of serological assays presented herein, the positive tests for L. infantum and D. immitis varied over the last 10 years' period (2009-2019), also in comparison with data available from the prior decade (1999-2009) [1]. Indeed, the number of positive serum samples of $L$. infantum in northern Italy increased in the examined 10 years' period (2009-2019) from 2.1\% (1999-2009; [1, 16]) to $21.6 \%$. The results also indicate that the number of cases positive for L. infantum has increased progressively in the past decade in the northern Italian regions, with an overall prevalence higher than that recorded in previous studies $[1,17]$. For example, in the province of Bologna (Emilia Romagna) the seroprevalence increased from $6.6 \%$ (i.e. 16 out of 245 animals examined in the period 2007-2009 [17]) up to $17.16 \%$ (i.e. 217 out of 1264 tests in this study). Overall, $L$. infantum exposure has spread progressively in the past decades from the endemic southern regions towards northern regions, making the whole Italian Peninsula endemic for this infection. Under these circumstances, the effect of relocation of infected animals from the South to the North of Italy could not be fully assessed in the study period. Nonetheleess, the northward spread of the main sand fly vectors, i.e. Phlebotomus perniciosus (Newstead) and Phlebotomus neglectus Tonnoir, which are now established in several provinces of the northern macroarea $[16,18,19]$, supports the evidence of $L$. infantum endemicity and the occurrence of new foci. In addition, clinicians' perception and awareness of the presence of CanL in non-endemic areas seem to be increased in the northern regions, with more than 21,545 tests performed, whereas the South remains the area with the largest number of tests requested (Table 1).

On the other hand, the cumulative prevalence of $D$. immitis infection greatly increased in central (7.7\%) and

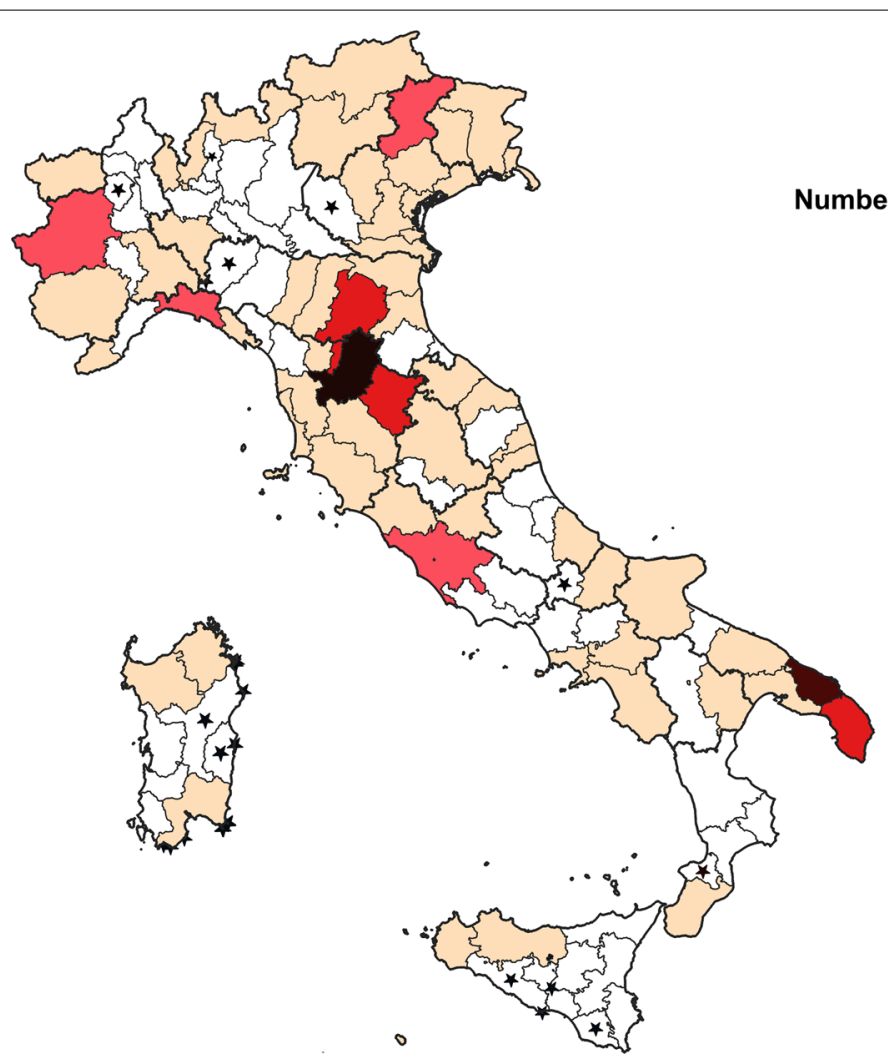

Number of positive samples (2009 - 2019)
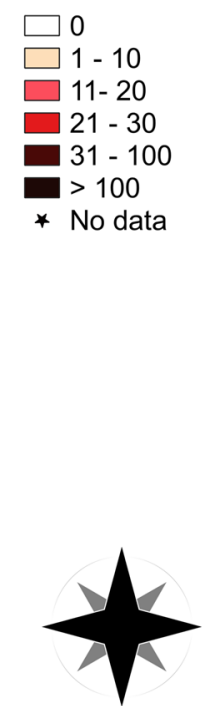

$\begin{array}{lllll}0 & 100 & 200 & 300 & 400 \mathrm{~km}\end{array}$

Fig. 5 Distribution map with number of cases (2009-2019) per province of HW in Italy 
southern Italy and islands (5\%), being higher than in the North (2.8\%), which was historically considered the sole endemic area $[1,20]$. The decreased prevalence of D. immitis infection in northern Italy regions could be a consequence of clinicians' awareness of the disease and thus of the continuous usage of chemoprophylactic programmes in this area. Nonetheless, resistance to ML has been demonstrated in $D$. immitis populations from this macroarea [21], which may represent a potential issue (not yet proven) for emergence of resistant strains. Moreover, the low number of tests performed for $D$. immitis infection (10.5\% of all the requested serological tests) throughout the Italian Peninsula also indicates the scant awareness of the occurrence of the disease, especially in the southern regions (Table 1). Given the increased prevalence in the Centre, the South and islands, clinicians should consider the occurrence of HW cases in nonendemic areas.

Furthermore, our analyses showed that the distribution patterns of $L$. infantum and D. immitis in Italy are related to a significant relationship between $L$. infantum /D. immitis positive results of the tests, the geographical provenience (i.e. macroarea) and study years (20092019). Conversely, a major hindrance of this study could be that the anamnesis of animals was not available (e.g. their travelling history from/to historically endemic areas for both diseases) [5, 22].

However, the clustering of positive samples in some spots of $L$. infantum exposure [e.g. the provinces of Turin (Piedmont) and Vicenza (Veneto), northern Italy; Fig. 3] and of D. immitis infection [e.g. in Brindisi and Lecce (Apulia), southern Italy; Fig 4] is consistent with previous reports. Endemic foci of CanL in the same provinces of Veneto [23] and Piedmont [24] confirmed the above mentioned epidemiological picture with a competent vector of L. infantum (i.e. P. perniciosus) captured in entomological surveys performed in that area [19]. In addition, other studies reported cases of CanL and human visceral leishmaniasis diagnosed in the same area, along with their vectors, P. perniciosus and $P$. neglectus [25].

The southward changing pattern of $\mathrm{HW}$ has been detailed in previous studies [26-29]. Hyperendemic $D$. immitis infection has been recorded in sheltered dogs from Apulia region (southern Italy) with the highest prevalence of infection (i.e. 44.2\%) in Europe [30]. The low prevalence of HW in Sicily and Sardinia could be explained by the small number of tests requested or no tests performed in many provinces from these islands. Indeed, earlier studies illustrated the islands to have a large number of diagnosed HW [31] as they are suitable for Dirofilaria spp. to thrive [13]. Specifically, Sardinia has the environmental, climatic and human activities (e.g. tourism with animal transportation) that could allow these nematodes to spread [5, 30]. Finally, central Italy showed a distribution pattern on which both pathogens are highly prevalent. In this macroarea, the prevalence of L. infantum was higher (29.6\%) of that indicated in previous surveys (up to 10\%) [32, 33]. Hence, central Italian regions are an important pathway for the spreading of CanL from southern to northern.

\section{Conclusions}

The large number of data analized strongly supports the above figure of distribution of L. infantum and D. immitis. Overall, results highlighted the changing distribution patterns of CanL vs HW in Italy over a 10-year period (2009-2019) in which the number of cases of CanL has increased in the northern Italy regions, and HW has endemic foci in the central and southern Italy and in islands. Moreover, given the number of tests requested, the overall clinicians' awareness in northern Italy is increasing for CanL and diminishing for HW. Data presented suggest that veterinarians and public health officials should be aware that CanL and HW are distributed throughout the country, thus epidemiological surveillance, preventative and control measures should be carried out to protect dogs from those CVBDs and reduce the risk of infection in humans.

\section{Supplementary information}

Supplementary information accompanies this paper at https://doi. org/10.1186/s13071-020-04063-9.

Additional file 1: Table S1. Contingency analysis summarizing the relationships between leishmaniosis (CanL) and dirofilariosis (HW) prevalence and the study year and region; the asterisk indicates a significant relationship with a study factor $(P<0.05)$; n.s., not significant $(P>0.05)$.

\section{Abbreviations}

CVBDs: canine vector-borne diseases; CanL: canine leishmaniosis; HW: heartworm disease; $\mathrm{Cl}$ : confidence interval.

\section{Acknowledgements}

Authors thank the responsible for the two diagnostic centres for providing results of the analyses herein examined (i.e. database A: San Marco Veterinary Clinic and Laboratory, Veggiano, Padova, Italy; database B: A.C.V.Triggiano S.R.L. Laboratorio di Analisi Cliniche Veterinarie, Triggiano, Bari, Italy).

\section{Authors' contributions}

JAMR and DO conceived the study. JAMR and GB performed the data curation, methods and anaylises of data. JAMR, GB and DO wrote the first draft of the manuscript. TF, FB, AZ, DO, RI and RP reviewed the manuscript. All authors read and approved the final manuscript.

\section{Funding \\ Not applicable.}

Availability of data and materials

All data generated or analyzed during this study are included in this published article and its additional file. 
Ethics approval and consent to participate

Not applicable.

\section{Consent for publication}

Not applicable.

\section{Competing interests}

The authors declare that they have no competing interests.

\section{Author details}

${ }^{1}$ Dipartimento di Medicina Veterinaria, Università degli Studi di Bari, Bari, Italy.

${ }^{2}$ Department of Agriculture, Food and Environment, University of Pisa, Pisa,

Italy. ${ }^{3}$ San Marco Veterinary Clinic and Laboratory, Veggiano, Padova, Italy.

${ }^{4}$ Boehringer Ingelheim Animal Health, Lyon, France. ${ }^{5}$ Faculty of Veterinary

Sciences, Bu-Ali Sina University, Hamedan, Iran.

Received: 21 February 2020 Accepted: 6 April 2020

Published online: 15 April 2020

\section{References}

1. Otranto D, Capelli G, Genchi C. Changing distribution patterns of canine vector borne diseases in Italy: leishmaniosis vs. dirofilariosis. Parasit Vectors. 2009;2(Suppl. 1):S2.

2. Colwell DD, Dantas-Torres F, Otranto D. Vector-borne parasitic zoonoses: emerging scenarios and new perspectives. Vet Parasitol. 2011;182:14-21.

3. Wilke ABB, Beier JC, Benelli G. Complexity of the relationship between global warming and urbanization-an obscure future for predicting increases in vector-borne infectious diseases. Curr Opin Insect Sci. 2019:35:1-9.

4. Killick-Kendrick R. Phlebotomine vectors of the leishmaniases: a review. Med Vet Entomol. 1990;4:1-24.

5. Genchi C, Mortarino M, Rinaldi L, Cringoli G, Traldi G, Genchi M. Changing climate and changing vector-borne disease distribution: the example of Dirofilaria in Europe. Vet Parasitol. 2011;176:295-9.

6. Morchón R, Carretón E, González Miguel J, Mellado Hernández I. Heartworm disease (Dirofilaria immitis) and their vectors in Europe-new distribution trends. Front Physiol. 2012;3:196.

7. Benelli G, Wilke ABB, Beier JC. Aedes albopictus (Asian tiger mosquito). Trends Parasitol. 2020. https://doi.org/10.1016/j.pt.2020.01.001.

8. Otranto D, Dantas-Torres F. Canine and feline vector-borne diseases in Italy: current situation and perspectives. Parasit Vectors. 2010;3:2.

9. Genchi C, Kramer LH, Rivasi F. Dirofilarial infections in Europe. Vector Borne Zoonotic Dis. 2011;11:1307-17.

10. Ferroglio E, Maroli M, Gastaldo S, Mignone W, Rossi L. Canine leishmaniasis, Italy. Emerg Infect Dis. 2005;11:1618.

11. Clemence RG, Sarasola P, Genchi C, Smith DG, Shanks DJ, Jernigan $A D$, et al. Efficacy of selamectin in the prevention of adult heartworm (Dirofilaria immitis) infection in dogs in northern Italy. Vet Parasitol. 2000;91:251-8

12. Cringoli G, Rinaldi L, Veneziano V, Capelli G. A prevalence survey and risk analysis of filariosis in dogs from the Mt. Vesuvius area of southern Italy. Vet Parasitol. 2001;102:243-52.

13. Otranto D, Brianti E, Gaglio G, Dantas-Torres F, Azzaro S, Giannetto S. Human ocular infection with Dirofilaria repens (Railliet and Henry, 1911) in an area endemic for canine dirofilariasis. Am J Trop Med Hyg. 2011;84:1002-4

14. Benelli G, Romano D, Kavallieratos N, Conte G, Stefanini C, Mele M, et al. Multiple behavioural asymmetries impact male mating success in the khapra beetle, Trogoderma granarium. J Pest Sci. 2017;90:901-9.

15. QGIS Development Team. QGIS geographic information system. Open Source Geospatial Foundation Project, Versão. 2015;2:7.

16. Maroli M, Rossi L, Baldelli R, Capelli G, Ferroglio E, Genchi C, et al. The northward spread of leishmaniasis in Italy: evidence from retrospective and ongoing studies on the canine reservoir and phlebotomine vectors. Trop Med Int Health. 2008;13:256-64.
17. Baldelli R, Piva S, Salvatore D, Parigi M, Melloni O, Tamba M, et al. Canine leishmaniasis surveillance in a northern Italy kennel. Vet Parasitol. 2011;179:57-61.

18. Morosetti G, Bongiorno G, Beran B, Scalone A, Moser J, Gramiccia M, Gradoni L, et al. Risk assessment for canine leishmaniasis spreading in the north of Italy. Geospat Health. 2009;2009(4):115-27.

19. Signorini M, Cassini R, Drigo M, di Regalbono A, Pietrobelli M, Montarsi $F$, et al. Ecological niche model of Phlebotomus perniciosus, the main vector of canine leishmaniasis in north-eastern Italy. Geospat Health. 2014;9:193-201.

20. Genchi C, Solari Basano F, Marrone RV, Petruschke G. Canine and feline heartworm in Europe with special emphasis on Italy. In: Proceedings of the Heartworm Symposium '98, 1-3 May, Tampa, Florida, USA; 1998. p. 75-82.

21. Bourguinat C, Lee A, Lizundia R, Blagburn B, Liotta J, Kraus M, et al. Macrocyclic lactone resistance in Dirofilaria immitis: failure of heartworm preventives and investigation of genetic markers for resistance. Vet Parasitol. 2015;210:167-78.

22. Brandonisio O, Carelli G, Ceci L, Consenti B, Fasanella A, Puccini V. Canine leishmaniasis in the Gargano promontory (Apulia, South Italy). Eur J Epidemiol. 1992;8:273-6.

23. Vascellari M, Natale A, Schievenin E, Miatto A, Brino A, Frangipane Di Regalbono A, et al. Descrizione di un nuovo focolaio di leishmaniosi canina nella Regione Veneto. Veterinaria. 2005;3:25-9.

24. Biglino A, Bolla C, Concialdi E, Trisciuoglio A, Romano A, Ferroglio E. Asymptomatic Leishmania infantum infection in an area of northwestern Italy (Piedmont region) where such infections are traditionally nonendemic. J Clin Microbiol. 2010;48:131-6

25. Capelli G, Baldelli R, Ferroglio E, Genchi C, Gradoni L, Gramiccia M, et al. Monitoring of canine leishmaniasis in northern Italy: an update from a scientific network. Parassitologia. 2004;46:193-7.

26. Di Cesare A, Castagna G, Meloni S, Milillo P, Latrofa S, Otranto D, et al. Canine and feline infections by cardiopulmonary nematodes in central and southern Italy. Parasitol Res. 2011;109:87-96.

27. Giangaspero A, Marangi M, Latrofa MS, Martinelli D, Traversa D, Otranto $D$, et al. Evidences of increasing risk of dirofilarioses in southern Italy. Parasitol Res. 2013;112:1357-61.

28. Del Prete L, Maurelli MP, Pennacchio S, Bosco A, Musella V, Ciuca L, et al. Dirofilaria immitis and Angiostrongylus vasorum: the contemporaneous detection in kennels. BMC Vet Res. 2015;11:305.

29. Sauda F, Malandrucco L, Macrì G, Scarpulla M, De Liberato C, Terracciano G, Fichi G, et al. Leishmania infantum, Dirofilaria spp. and other endoparasite infections in kennel dogs in central Italy. Parasite. 2018;25:2.

30. Panarese $R$, latta R, Latrofa MS, Zatelli A, Ignjatović Ćupina A, Montarsi F, Pombi M, Mendoza-Roldan JA et al. Hyperendemic Dirofilaria immitis infection in sheltered dog population: an expanding threat in the Mediterranean regions. Int J Parasitol. 2020 in press.

31. Genchi M, Rinaldi L, Venco L, Cringoli G, Vismarra A, Kramer L. Dirofilaria immitis and D. repens in dog and cat: a questionnaire study in Italy. Vet Parasitol. 2019;267:26-31.

32. Maresca C, Scoccia E, Barizzone F, Catalano A, Mancini S, Pagliacci T, et al. A survey on canine leishmaniasis and phlebotomine sand flies in central Italy. Res Vet Sci. 2009;87:36-8.

33. Vulpiani MP, lannetti L, Di Mattia T, Dalla Villa P. Leishmania infantum in a Central Italy dog shelter: retrospective study of serologic reactivity during a 4-year period in a confined dog population subjected to preventive and therapeutic treatment. Vet Parasitol. 2009;160:190-7.

\section{Publisher's Note}

Springer Nature remains neutral with regard to jurisdictional claims in published maps and institutional affiliations. 